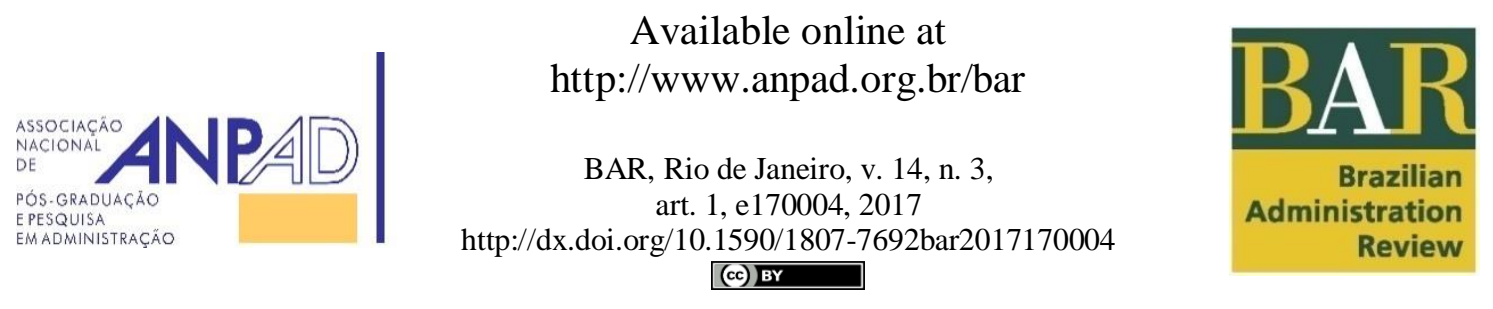

\title{
Identity in Family Firms: A Theoretical Analysis of Incentives and Contracts
}

Marcelo Sanches Pagliarussi ${ }^{1}$

Cristiano Costa ${ }^{2}$

Universidade de São Paulo ${ }^{1}$

Unisinos $^{2}$

Received 19 January 2017; received in revised form 24 July 2017 (this paper has been with the authors for two revisions); accepted 25 July 2017; first published online 23 August 2017. Editor's note. Vera Cançado served as Action Editor for this article. 


\begin{abstract}
We developed a principal-agent model that coherently and parsimoniously explains previous findings from research on executive compensation in family firms. We introduce organizational identification in the model in order to capture the effect of family firms' distinctive characteristics on the agent's behavior. After describing the optimal incentive contract under moral hazard, we show that the dispersion in the optimal wage profile decreases as the level of organizational identification of the agent increases. Moreover, we show that agency costs decrease as the level of organizational identification of the agent increases. Our results imply that hiring a strongly identified family manager will result in greater expected wealth to the principal and better risk sharing between the parties. We further analyze two interrelated factors that may drive changes in contract parameters: the degree of altruism in the family firm, and the level of collectivism of the society in which the firm is located.
\end{abstract}

Key words: incentives; family firms; organizational identification; altruism; collectivism. 


\section{Introduction}

The seminal works of Schulze, Lubatkin, Dino and Buchholtz (2001) and Gomez-Mejia, NunezNickel and Gutierrez (2001) presented agency conflicts in family firms in a new perspective, and stimulated subsequent research efforts. Currently, it is fairly accepted that family firms are less impacted by problems that arise from the separation of ownership and management (Carney, Van Essen, Gedajlovic, \& Heugens, 2015; Chrisman, Kellermanns, Chan, \& Liano, 2010; Salvato \& Moores, 2010; Songini, Gnan, \& Malmi, 2013). Existing empirical evidence appears to support this view both for small (Chrisman, Chua, \& Litz, 2004) and large family firms (Anderson \& Reeb, 2003; Villalonga \& Amit, 2006).

Complementarily, studies on executive compensation in family firms found out that family CEOs' compensation levels are lower and they receive less incentive-based pay in comparison with nonfamily CEOs (Cruz, Gómez-Meija, \& Becerra, 2010; Gomez-Mejia, Larraza-Kintana, \& Makri, 2003; McConaughy, 2000). The authors articulated distinct rationales to explain their results, such as the incentive alignment effect that results from family control (McConaughy, 2000), or the proposition that family ties shield the CEO's welfare and insulate her from bearing excessive personal risk (Cruz et al., 2010; Gomez-Mejia et al., 2003).

Block, Millán, Román and Zhou (2015) also observed that family employees received lower wages, compared to regular employees. They articulate utility theory and the theory of compensating wage differentials to sustain that family employees derive utility from working in their own family firm, in complement to wages and nonpecuniary job characteristics. Baek and Fazio (2015) also found out that family firms are less prone to use incentives in agency contracts, especially when the family CEO is paid material dividends. The authors interpreted their results as evidence that family firms do not closely conform to the tenets of agency contracting in compensation, as suggested by Schulze et al. (2001) and Gomez-Mejia et al. (2001).

The precedent discussion suggests that the issue of incentive compensation in family firms merits further investigation, particularly with regard to the differential effects of incentive compensation in these firms, for both family and non-family executives (Prencipe, Bar-Yosef, \& Dekker, 2014). Moreover, the existence of competing rationales that explain the same pattern of findings in the literature of executive compensation in family firms stresses the need for a unifying theoretical framework for the phenomenon.

Thus, we aimed at developing a principal-agent model that describes a situation in which a family firm needs to fill a managerial position, and the family principal has the option to choose a family member or an outsider manager. Figure 1 describes the sequence of events used in the model.

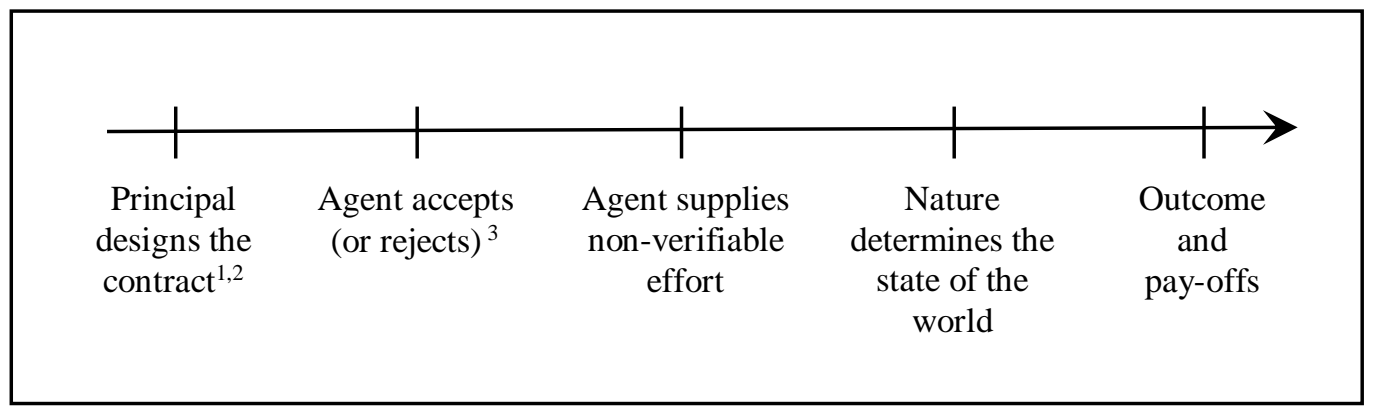

Figure 1. Sequence of Events

Legend: ${ }^{1}$ The principal may have behaved altruistically towards the agent in the past. ${ }^{2}$ The firm may operate in a collectivist country. ${ }^{3}$ The agent may experience a positive level of organizational identification.

Source: adapted from Macho-Stadler, I., \& Pérez-Castrillo, J. D. (2001). An introduction to the economics of information: Incentives and contracts (p. 9). New York: Oxford University Press. 
We show how the presence of family ties between principal and agent change the optimal incentive contract parameters. We further analyze two interrelated factors that may drive changes in contract parameters: an organizational factor, represented by the degree of altruism in the family firm, and a situational factor, represented by the level of collectivism of the society in which the firm is located. We use altruism as the "the endogenous propensity for parents to transfer predefined socially embedded values and norms to their offspring" (Lubatkin, Durand, \& Ling, 2007, p. 1026). Collectivism, in this work, "pertains to societies in which people from birth onwards are integrated into strong, cohesive in-groups, which throughout people's lifetime continue to protect them in exchange for unquestioning loyalty" (Hofstede, 1991, p. 51).

We assume that the principal wants to design a contract with a wage profile that induces the agent to choose a high level of effort. In this situation, our model's main results indicate that family firms that are able to induce higher levels of organizational identification in their agents, by means of altruistic behavior towards family members, will bear lower agency costs in comparison with firms in which altruism is absent. In addition, we show that when the level of identification is positive, both the dispersion in the optimal wage profile and the expected wage associated with the agent's higher effort levels are reduced. Furthermore, in collectivist societies, the wage structure will also have a lower expected value and a lower dispersion across different outputs compared with individualist societies.

The use of formal models to analyze governance and incentives issues in family firms is very scarce, with the notable exceptions of Block (2011), and Berghe and Carchon (2003). The use of agency theory in the domain of family firms is sometimes criticized with the argument that such firms have more complex goal systems, including non-economic objectives besides economic incentives (Astrachan \& Jaskiewicz, 2008; Zellweger \& Astrachan, 2008). Another critic is that principal-agent models do not account for the behavioral learning effects that arise from repeated social interactions, such as the emergence of trust between the parties (Jaskiewicz \& Klein, 2007).

By introducing organizational identification in the principal-agent framework we built a model that can be more generally used in the analysis of executive compensation in family firms, since our model captures the influence of the degree of altruism, trust, emotions and sentiments on the contracts between family principals and managers of the family firm. The inclusion of organizational identification in our model also increases its cross-cultural relevance. Our rationale suggests that organizational identification is affected by the level of collectivism that characterizes a society, both directly and indirectly through the influence of the altruism towards family and nonfamily managers in the family firm.

Therefore, our model is both family firm specific and it fills a gap in the knowledge about how formal and informal institutions at a country level affect behaviors in family firms (Carney et al., 2015; Pindado \& Requejo, 2014). In consonance with Whetten (1989), we show that the inclusion of organizational identification in the model significantly alters our understanding of the phenomena of executive compensation in family firms.

\section{Related Literature}

\section{Executive pay and incentive compensation in family firms}

Economic organizations confront the challenge of coordinating specialized producers in a cooperative way, in order to capture the efficiency gains of specialization (Milgrom \& Roberts, 1992). An important part of the challenge arises from the fact that self-interested individuals do not bear the full responsibility of their actions, and thus may not feel motivated to act in accordance with a plan. Studies based on agency theory suggest the use of incentives, linking performance with payment, as a remedy for the problem of motivation. 
In the domain of family firms, McConaughy (2000) argued that executives who are members of the controlling family already have greater incentives for maximizing firm value, since they have claims on family resources. Thus, it is expected that family CEOs will demand lower compensation levels than nonfamily CEOs. The author examined CEO compensation in 82 founding-family-controlled firms in which 47 CEOs were members of the founding family and 35 were not, and observed that family CEOs' compensation levels are lower and that they receive less incentive-based pay.

In the same vein, Block et al. (2015) presented evidences suggesting that family employees earn less and exhibit greater job satisfaction than nonfamily employees. The authors interpret their findings as evidence that family employees extract utility from working in their family business, which makes them willing to accept lower wages in exchange for the additional utility.

Similarly, Speckbacher and Wentges (2012) observed that founding family involvement in the top management team is associated with less use of incentive practices. The authors explain that employment relationships between family members are characterized by trust, reciprocal altruism, and shared values, which can serve as a substitute for incentive contracts, since they help to align interests between the parties.

Baek and Fazio (2015) also observed that family firms design agency contracts with less incentive mechanisms for family CEOs, especially when they receive material dividends. Interestingly, the authors offer a distinct rationale to explain their results, suggesting that family firms deviate from the tenets of agency contracting, as suggested by Schulze et al. (2001) and Gomez-Mejia et al. (2001).

Complementarily, Cruz, Gómez-Mejia and Becerra (2010) reasoned that agency relationships in family firms involve parties that are highly interdependent, work closely with each other and are emotionally attached. Consequently, the principal's perception of agents' benevolence will be greater, thus reducing the perceived threat of opportunism. The authors observed, in a sample of 122 Spanish family-owned firms, that when the firm's CEO (as principal) and its top management team (as agents) share family ties, the resulting agency contract contains features that weaken firm protection and strengthen the agent's position.

In sum, issues regarding the level of compensation and the intensity of incentives offered to family managers still constitute interesting research opportunities, since there are several contending explanations for the same pattern of results. In the next section, we present the basic principal-agent model that is widely used in the corporate governance literature to analyze incentive problems in organizations.

\section{Principal-agent models under moral hazard}

An agency relationship refers to several types of situations in which an individual legally appoints another individual to act or conduct business on her behalf. For instance, there is an agency relationship when a shareholder grants decision rights to a manager based on her belief that the manager has superior skill or information to make investment decisions.

Usually, the manager is considered a risk-averse self-interested agent, whereas the shareholder is modeled as a risk-neutral self-interested principal. The manager is contracted to carry out actions on behalf of the principal, based on the following sequence of events (Macho-Stadler \& Pérez-Castrillo, 2001):

1. The principal designs the contract and offers it to the agent;

2. The agent chooses whether or not to accept the contract, based on the expected utility provided, in comparison with the other opportunities available to him;

3. The agent chooses an action to be exerted on behalf of the principal. 
A set of concurrent factors precludes automatic alignment of interest between the parties. Informational asymmetries make the manager's labor input hard to verify, up to the point that his actions are considered unobservable (Hart \& Holmström, 1987). This situation generates incentive problems, since it allows the agent to pursue goals of his own at the expense of the principal. Such hidden action problem is termed in the literature as moral hazard (Macho-Stadler \& Pérez-Castrillo, 2001).

The analysis of agency relationships is focused on finding an optimal response to the incentive problem, assuming that the principal can design a contract that induces the agent to choose appropriate actions voluntarily (Prendergast, 1999). It is usual to represent the action chosen by the agent as effort $e$, though there are other plausible examples. In the simplest hidden action model the manager has only two actions to choose from, identified as either providing a high effort $\left(e^{H}\right)$ or a low effort $\left(e^{L}\right)$ (Hart \& Holmström, 1986). The agent's choice, along with other exogenous factors, influence the outcome of the firm, denoted as $x$, which is observable and can be contracted on (Lambert, 2001). The basic idea is that greater effort increases the likelihood of better results.

The principal collects the results generated by the agent's actions, and must pay the agent for his work. The principal wants to maximize expected profits $(x-w)$. She cannot observe the agent's actions, but she can condition payments on $x$, since the outcome is informative about the agent's actions. After the outcome is observed, the agent is paid an amount $w$ according to the compensation scheme defined in the contract.

Since the agent obtains utility from his wage and disutility from the effort, his utility function can be defined by these components, $U(w, e)=u(w)-v(e)$ (Macho-Stadler \& Pérez-Castrillo, 2001). In this abstraction, the conflict of interests between principal and agent arises due to three elements (Macho-Stadler \& Pérez-Castrillo, 2001): while greater efforts make better results more likely, the principal collects the benefits generated by the effort, whereas the agent bears all the cost of effort. Thus, the agent is not naturally motivated to choose a high effort level.

The principal then must design an optimal contract that maximizes her objective $(x-w)$, subject to two constraints: the agent chooses an action that maximizes $U(w, e)$ and the expected utility of the contract must exceed his reservation utility (Lambert, 2001). Since the principal wants to implement the higher effort level, she must provide the right incentives to the agent, based on information that can be included in the contract (Hart \& Holmström, 1986). As Holmstrom (1979) has shown, the presence of information asymmetries and other restrictions force the contract to be second best, in the sense that it sacrifices some risk-sharing benefits in order to provide the agent with the right incentives. The author explains that the resulting contract, which is based on imperfect information about the agent's actions, will allocate excessive responsibility on the risk-averse agent.

\section{Limitations of the principal-agent model in describing agency relationships in family firms}

Analytic methods built on the abstractions presented in the previous section are widely used in principal-agent analysis in the economic literature. Yet, we notice an infrequent use of formal models in the analysis of the governance of family firms. Two notable exceptions are Block (2011), and Berghe and Carchon (2003).

Block (2011) analyzed a principal-agent relation in which the agent is a nonfamily manager and his short-term interests are in contrast with the long-term goals of the business-owning family, representing the principal. Block's (2011) results suggest that in such situation it will pay the principal to offer a fixed-wage contract to a nonfamily manager or to rely on subjective performance evaluations.

Berghe and Cachon (2003) modeled a situation in which the founder-manager of a family business transfers management to a close relative, say his daughter, assuming that both father and daughter have the same information before and during the contractual relationship, and that the daughter's effort is verifiable. The authors then showed that when the wage paid to the daughter fully reflects the distribution of risk between her and the father, no conflicts of interest will arise. 
A plausible explanation for the scarce application of formal models in the analysis of agency conflicts in family firms rests on the simplifying assumptions of the principal-agent model, and its reductionist approach. The model has been criticized for engendering an undersocialized view of principals and agents (Lubatkin, Lane, Collin, \& Very, 2007). Also, it does not allow for a dynamic analysis, in the sense that it neither describes what happens after goal alignment is realized, nor how the firm's governance change over time (Madison, Holt, Kellermanns, \& Ranft, 2015).

Moreover, Corbetta and Salvatto (2004) argue that the human assumptions used to build agency theory do not fully apply to the realm of family firms, since family goals, the degree of altruism, trust, emotions and sentiments influence on relational contracts. Thus, the owning family exerts a profound impact on the prevailing model of man in family firms, and the authors call for a conceptual framework that accommodates both pro-organization behaviors and self-serving motives when individuals act aiming at maximizing potential performance within the family firm.

Therefore, the standard principal-agent model must be amended in order to enhance its potential applications to the context of family firms, because these organizations are typically characterized as relying on mutual trust, intra-familial altruism in its purest sense, and clan-based collegiality (Corbetta \& Salvatto, 2004). In the next section, we discuss how the characteristics of family firms induce modifications in the basic principal-agent model when it comes to analyze agency relationships in these firms.

\section{A Principal-Agent Model for Family Firms}

The family is the evident source of distinctiveness of family firms. In essence, family influence produces an intertwinement of factors that shapes the firm's goals, strategies, and structure (Chrisman, Chua, \& Sharma, 2005; Chua, Chrisman, \& Sharma, 1999). Due to family influence, the family firm configures a unique governance archetype, encompassing strong incentives for parsimony and efficiency, authority structures marked by a concentration of power, and a relative freedom from accountability to third parties (Carney, 2005).

An essential aspect of family governance in the study of agency relationships is the process by which family managers are introduced to the firm. Typically, their involvement begins long before they formally sign an employment contract (Block, 2011; Verbeke \& Kano, 2010). Since the family member enters in the firm bringing the family's values and belief system already internalized, the extended process by which he or she is socialized in the firm promotes the merging of family and business values.

The family values and belief system interact with the business systems to create the family firm identity (Davis, Allen, \& Hayes, 2010; Sundaramurthy \& Kreiner, 2008; Zellweger, Eddleston, \& Kellermans, 2010). Arguably, a family is a social group in which each member is responsible for promoting the group's overall welfare, as well as has access to the benefits such as food, shelter, emotional support, identity, and protection (Schulze \& Gedajlovic, 2010). Transferred to the family business, this conjunction of co-dependency, family bonds, norms of reciprocity, history and extended periods of experience promotes the alignment of individual and organizational goals (Mustakallio, Autio, \& Zahra, 2002; Tagiuri \& Davis, 1996; Verbeke \& Kano, 2010; Zahra, Hayton, Neubaum, Dibrell, \& Craig, 2008).

The concept of organizational identification is instrumental to understand how the behavior of family members that work in the family firm is affected by the merge of family values and business systems that bring forth the family firm identity. Organizational identification is the feeling of belonging to groups such as clubs, religious groups, places of employment and occupations (Bhattacharya, Rao, \& Glynn, 1995; Turner, 1982). Individuals will identify with organizations that they believe have the same characteristics that they see as defining themselves (Ashforth \& Mael, 1996; Dutton \& Penner, 1993). Furthermore, if an organization's distinctive characteristics impart enhanced status to individuals, and 
thus positively reinforce their self-concepts, individuals are likely to identify with it (Dukerich, Golden, $\&$ Shortell, 2002). Two specific outcomes of organizational identification are essential to the present work: increased loyalty and the display of cooperative behaviors towards the organization (Adler \& Adler, 1988; Ashforth \& Mael, 1989; Mael \& Ashforth, 1992).

A number of recent studies have provided evidence that organizational identification can indeed attenuate agency costs. Abernethy, Bouwens and Kroos (2017) observed that managers with incentivebased compensation who strongly identify with the firm engage in lower levels of opportunistic earnings manipulation. Boivie, Lange, McDonald and Westphal (2011) found out that CEOs with higher levels of organizational identification are less prone to take actions that might harm his/her firm or its image. Also, the authors observed that CEO organization identification is a substitute for external controls mechanisms with respect to agency problems, therefore reducing the overall agency costs. Finally, Heinle, Hofmann and Kunz (2012) presented theoretical arguments suggesting that firms which successfully implemented identity initiatives can undermine managers' effort in short-term and boost long-term value generation.

From the previous discussion, it is expected that family members working in the family business are likely to feel strongly identified with the organization. As Sharma and Irving (2005) pointed out, the family business constitutes a focal point in the lives of many family members, thus influencing even their sense of self.

In this sense, we propose that a principal-agent model applied to family firms, which can describe the situation in which a family member is appointed as a manager, must allow the agent to identify more or less strongly with the family firm, and the higher identification should be associated with a proorganizational behavior. Inspired by Akerlof and Kranton (2005), we developed a variation of the principal-agent model under moral hazard that includes the concept of organizational identification. Our research improves Akerlof and Kranton (2005) by developing an analytical model that allows us to derive formal propositions, including a relevant result about wage dispersion and the level of organizational identification, which was not discussed by the authors. Our model also contributes to the literature by adding organizational and situational factors, as the model can also be used as a basic setup to discuss cultural aspects that may affect the design of incentive contracts, such as individualism and collectivism. The model describes a situation in which the principal wants to design a contract with a wage profile that induces the agent to choose a high level of effort. The agent can be a member of the principal's immediate family, a more distant relative or a nonfamily member, and we will show how the degree of closeness influences the optimal contract parameters.

\section{The agent's utility function}

In our model, the agent is risk-averse and his utility depends on the level of effort, $e$, chosen by him, and from the expected wage, $w$, which depends on the output of the task he is assigned to perform. The agent gains utility from wages and experiences disutility of effort, the latter being dependent on the level in which the agent identifies himself with the family firm, $i$. We define identification as a continuous variable, $0 \leq i \leq 1$, to characterize both extremes: not identified, or completely identified with the family firm. At $i=0$ the agent had neither prior involvement with the firm nor with the controlling family. The other extreme, $i=1$, means that the agent is a member of the immediate family that controls the firm, and has fully interiorized the values and the belief system of the family firm.

We choose $i$ as the continuous variable, rather than a discrete one, to allow greater variety in the representation of organizational identification states in the family firm. For instance, a more distant relative of the controlling family may partially feel like a member of the organization at the outset, especially if he considers that the offer he is receiving relates to his family status. Moreover, defining identification as a continuous variable also accommodates variation in the ability of the controlling family in inducing the alignment of individual and organizational goals in the family firm. 
The agent can choose between two levels of effort: high $\left(e^{H}>1\right)$ or low $\left(e^{L}=0\right)$. The value of zero was chosen for normalization, and it does not mean that the agent is not making any effort. The output of the task, $y$, can be high $\left(y^{H}\right)$ or low $\left(y^{L}\right)$, and it depends on how much effort the agent chooses. When the agent chooses the high effort, the output will be high with probability $p \in(0,1)$. However, if the agent chooses the low effort the output will be high with probability $q \in(0,1)$, such as $q<p$. Although a higher effort is associated with the higher output, the probabilistic relationship imposes that the outcome also depends on random factors that neither the principal nor the agent can control. Thus, the agent cannot perfectly choose the final output, and the principal cannot determine the actions taken by the agent based on the outcome.

The agent's utility function is

$$
U(e)=E[\sqrt{w(y(e))}-e+i \sqrt{e}]
$$

where $U(e)$ is the level of utility when the agent chooses effort $e ; w(y(e))$ is the wage received by the agent when his action, $e$, results in an output $i$; and $E[$.$] denotes the expected value. The risk$ aversion of the agent towards an uncertain outcome is captured by the concavity of the utility function in $w(y(e))$. The last term on the right side of Equation 1 is inspired by Akerlof and Kranton (2005) and represents the effect of organizational identification on the agent's utility level. If $i=0$, then the utility function has the same characteristics as the original utility functions used in standard moral hazard problems, namely increasing in wages and decreasing in effort. However, if $i>0$, the cost of choosing a higher level of effort decreases. Therefore, in our setting the more identified the agent feels with the family firm, the lower is his cost of choosing a high level of effort. This modification in the standard principal-agent model under moral hazard is the critical feature of our model that enhances its applicability to the domain of family firms.

\section{The utility of the principal}

We assume that the principal is risk-neutral and her utility depends on the output of the agent's work and the wages paid to him. The principal's utility is presented in Equation 2:

$$
V(e)=E[y(e)-w(y(e))]
$$

where $y(e)$ is the output when the agent chooses a level of effort $e ; w(y(e))$ is the wage paid to the agent when his actions result in an output $y$; and $E[$.$] denotes the expected value.$

In the next section, we solve the optimization problem in order to demonstrate how the optimal contract parameters are affected by the presence of family ties between principal and agent in a family firm. We also provide numerical examples of our analysis, by attaching numbers to the parameters described above, and further improving our analysis as we illustrate what happens when identification and uncertainty about outcomes vary simultaneously.

\section{Analysis}

The timing of the model, as described in Figure 1, is as follows: (a) the principal designs a contract and offers it to the agent; (b) the agent chooses the level of effort; and (c) the output is realized and wage is paid.

\section{Deriving optimal contract parameters and propositions}

In this section, we investigate how optimal parameters of incentive contracts change conditional on the degree to which the agent identifies himself as a member of the family firm. Our model describes a situation in which the principal observes the final output, but does not observe the effort level chosen 
by the agent. Therefore, we allow the principal to offer a wage profile that depends on the output of the task performed by the agent. Let $w^{H}$ denote the salary paid to the agent when the output is $y^{H}$, and $w^{L}$ the salary paid when the output is $y^{L}$. The principal wants to design a wage profile to induce the agent to choose the high level of effort, $e^{H}$. Any contract offered by the principal has to satisfy the agent's rationality constraint (RC): the expected utility of working at the firm choosing the high level of effort must be at least as good as the agent's outside option, $\bar{U}$. This constraint is represented by the following inequality:

$$
E\left[U\left(e^{H}\right)\right] \geq \bar{U}
$$

Additionally, the wage profile designed by the principal must induce the agent to choose a high level of effort over the low level. The wage profile thus has to satisfy the following incentive compatibility constraint (IC):

$$
E\left[U\left(e^{H}\right)\right] \geq E\left[U\left(e^{L}\right)\right]
$$

The principal's problem is to find a pair of wages $\left(w^{L}, w^{H}\right)$ that maximize the principal's expected utility while satisfying RC (Equation 3 ) and IC (Equation 4). Proposition 1 presents the optimal wage profile when the principal wants to induce a high level of effort.

Proposition 1: The optimal contract $\left(w^{L *}, w^{H *}\right)$ is:

$$
\begin{aligned}
& w^{L *}=\left\{\bar{U}-\frac{q}{p-q}\left[e^{H}-i \sqrt{e^{H}}\right]\right\}^{2} \\
& w^{H *}=\left\{\bar{U}+\frac{(1-q)}{p-q}\left[e^{H}-i \sqrt{e^{H}}\right]\right\}^{2}
\end{aligned}
$$

Proof: See Appendix.

There is a wage differential between $w^{L *}$ and $w^{H *}$ that induces the agent to choose the higher effort. The difference in wages is generated by the term on the right-hand side of Equations 5 and 6 , which is positive, and this creates a width that depends on the probabilities of observing a high level of output at the highest level of effort. In particular, when there is no organizational identification, $i=0$, represented by the case in which the agent is neither a member of the controlling family nor has worked at the family firm, the wage differential is the same as observed in the standard moral hazard model.

\section{Understanding the consequences of the presence of family ties between principal and agent}

Family members working in the family business experience the integration of belief systems originating both from the family and from the business (Zellweger et al., 2010). This context is expected to induce strong feelings of organizational identification on family members, and incidentally, greater commitment and pro-organizational attitudes.

In our model, a family member that assumes the role of the agent is described as an individual who feels positively identified with the family firm, which makes it less costly for him to choose a high effort level. As observed in Proposition 1, this affects directly the optimal contract parameters, since $w^{L *}$ is increasing on $i$, while $w^{H *}$ is decreasing on $i$. Therefore, we propose that the presence of family ties between principal and agent reduces the size of the wage differential necessary to induce the agent to choose the higher effort level. Formally:

Proposition 2: When the agent experiences a positive level of organizational identification, the dispersion in the optimal wage profile decreases as the level of organizational identification increases. Proof: See Appendix. 
Proposition 2 implies that when a member of the controlling family is hired to manage the firm, he will need less incentives to align his interests with the principal, since he is, by definition, positively identified with the family firm. Interestingly, it follows from Proposition 1 that this family agent will also demand a higher salary when the output is low, since he is risk-averse. Nevertheless, in the case of complete identification, $i=1$, the wage differential reaches its minimum.

Further analysis shows that, because the wage is an increasing and convex function of the organizational identification level, a decrease in $w^{H *}$ is of greater magnitude than an increase in $w^{L *}$, reducing the expected wage $E[w]=p w^{H *}+(1-p) w^{L *}$ paid to the agent. Thus, we can then state that:

Proposition 3: Agency costs are lower when the agent experiences a positive level of organizational identification. Proof: See Appendix.

Propositions 2 and 3 combined imply that hiring a family manager who is positively identified with the family business will result in a greater expected wealth to the principal. Another interesting result from our model is that hiring a family manager will result in better risk sharing between the parties, since the family manager will face less risk in his proceeds, in comparison with the optimal contract that would be offered to a nonfamily manager who does not identify himself as a member of the family firm.

\section{Numerical examples}

In this section, we present two numerical examples in order to highlight the differences between hiring a positively identified family agent versus a nonfamily manager who does not identify himself with the family firm. The use of numerical examples enriches the analysis as we can visualize the effects of identification over the agency costs and wage differential for each level of uncertainty in the activity. This illustration helps us to understand, using only figures, what happens when we change two variables (uncertainty and identification) simultaneously, which otherwise can be done by using derivatives, as presented in the Appendix.

We illustrate differences on the dispersion of the wages paid to the agent and the agency costs incurred by the principal. Both effects are analyzed with respect to changes in the organizational identification level $(i)$ and in the uncertainty in the output when the agent chooses high effort $(p)$. In order to do so, we fixed the parameters that we are not using in the analysis. We fixed $q=0.2$ to satisfy the requirement that $q<p$; we normalized $e^{L}=0$, as the model only requires it to be non-negative; we fixed $e^{H}=10$ as the model requires it to be positive and greater than $e^{L}$; and we fixed $\bar{U}=50$ as it is a measure of opportunity cost and has to be positive. It must be clear that changing the values of these parameters, as long as the requirements of the model are satisfied, does not change the analysis. Table 1 presents the basic parameters used in the numerical examples.

Table 1

Fixed Parameter Values

\begin{tabular}{ccc}
\hline Parameter & Definition & Value \\
\hline$q$ & Probability of getting high output under low effort & 0.2 \\
$e^{H}$ & Higher effort level & 10 \\
$e^{L}$ & Lower effort level & 0 \\
$\bar{U}$ & Agent's reservation utility & 50 \\
\hline
\end{tabular}




\section{The effect of organizational identification on wage dispersion}

We know from Proposition 2 that when the agent experiences a positive level of organizational identification, the dispersion in the optimal wage profile $\left(w^{H *}-w^{L *}\right)$ decreases as the level of organizational identification increases. Figure 2 presents this relationship for various levels of high output uncertainty $(p)$.

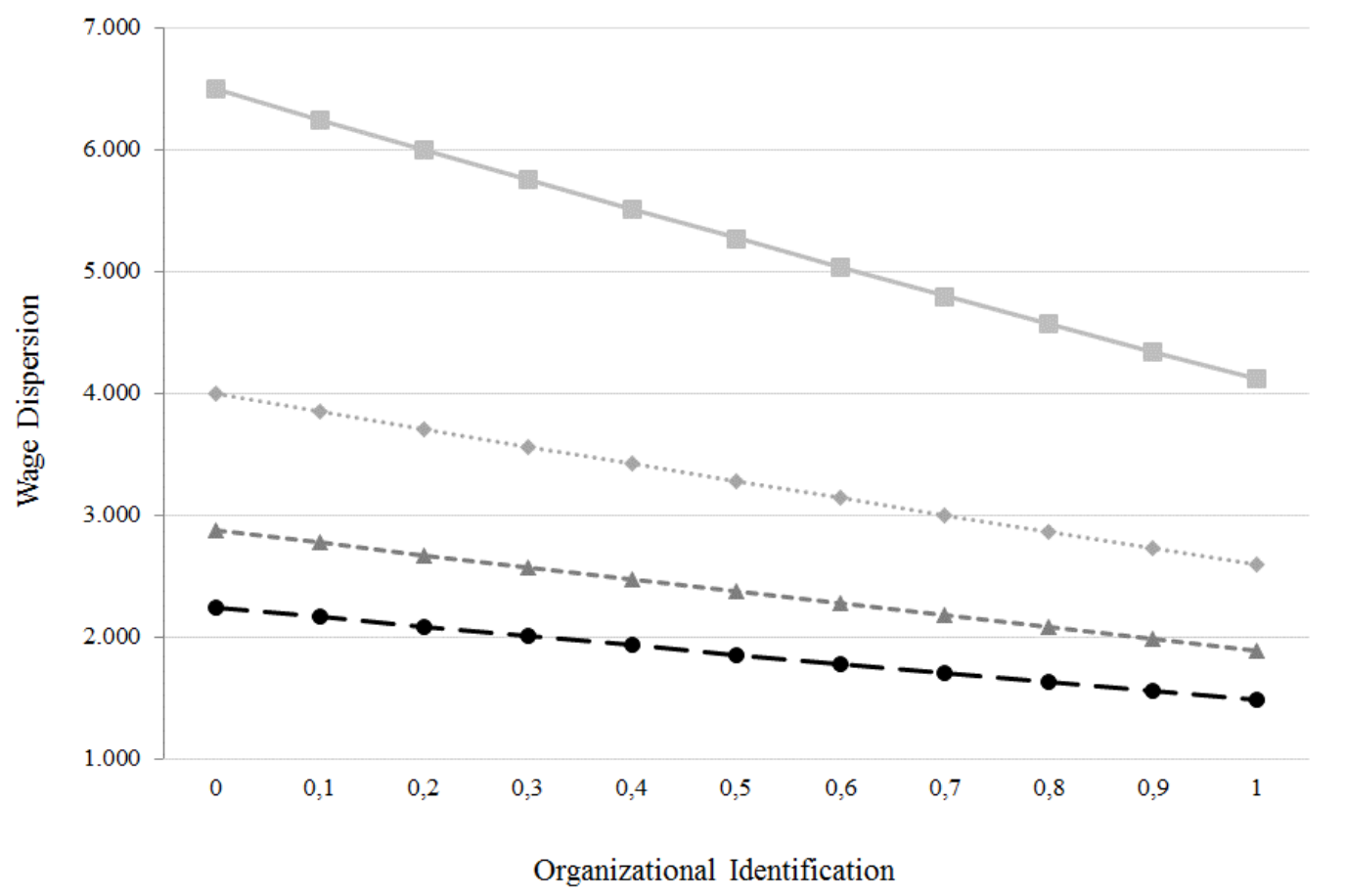

$$
\begin{array}{ll}
-p=0.4 & \cdots \cdot p=0.5 \\
-p-p=0.6 & \rightarrow \cdot p=0.7
\end{array}
$$

Figure 2. Relationship for Various Levels of High Output Uncertainty $(p)$

This figure presents the impact of organizational identification (i) on the wage difference $\left(w^{H *}-w^{L *}\right)$ derived on Proposition 1. Each line represents the wage differential for a given probability $(p)$ of obtaining a high output when the agent exerts high effort.

The graph illustrates that, for high levels of uncertainty about output of choosing high effort (lower values of $p$ ), the effect of organizational identification on wage dispersion is stronger, as we observe a steeper slope. For our set of parameters, when the uncertainty is high $(p=0.4)$, under full organizational identification $(i=1)$ the wage dispersion is $\$ 4,120$, while it is $\$ 6,500$ when there is no organizational identification $(i=0)$. The gains from organizational identification in this example are $\$$ 2,380 . When the uncertainty is not high $(p=0.7)$, the wage differential under full identification is $\$$ 1,480 , and under no identification, it is $\$ 2,240$.

Interestingly, these results show that hiring a highly identified family manager is even more beneficial for the firm when its business model is based on an idiosyncratic bundle of resources and knowledge, a common situation for family firms (Chrisman, Chua, \& Steier, 2005; Habbershon, 2006; Lee, Lim, \& Lim, 2003). Besides being positively identified with the firm, the family manager is expected to have superior knowledge about the firm's business model by virtue of his previous involvement with it. Hence, he will not only demand less incentive to exert a higher effort, but he will also be more able to produce a higher output when choosing that effort. 


\section{The effects of organizational identification on agency costs}

Another feature of our model is that agency costs, represented by the expected wage paid to the agent, are lower when the firm hires a positively identified family manager, as stated in Proposition 3. We use a numerical example to show that agency costs decrease as the level of organizational identification increases, as Figure 3 shows.

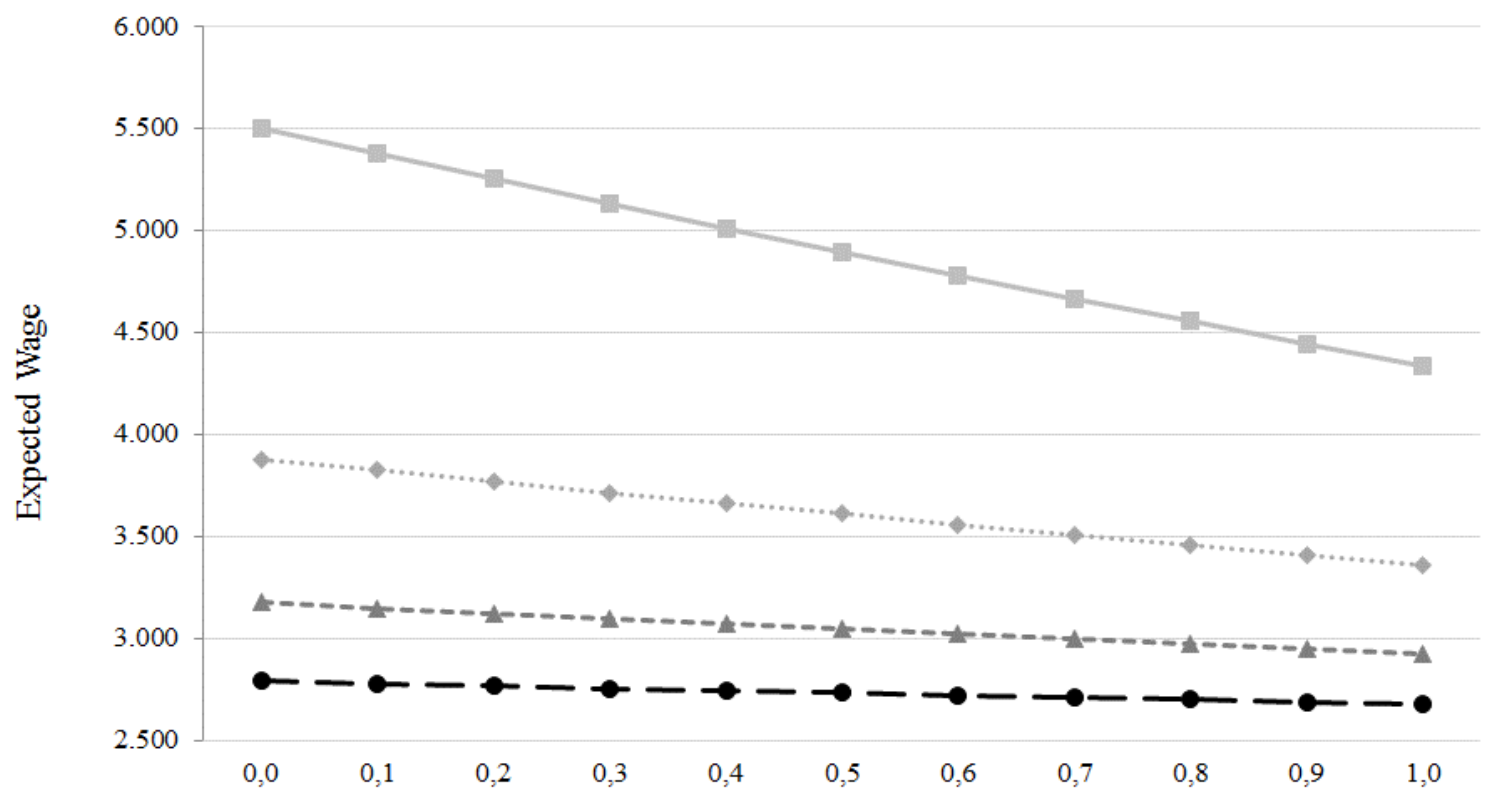

Organizational Identification

$$
\begin{aligned}
& \longrightarrow \mathrm{p}=0.4 \quad \cdots \rightarrow \mathrm{p}=0.5 \\
& \rightarrow-\mathrm{p}=0.6 \quad \rightarrow \mathrm{p}=0.7
\end{aligned}
$$

Figure 3. The Impact of Organizational Identification on the Expected Wage

This figure illustrates the impact of organizational identification (i) on the expected wage, $E[w]$, derived on Proposition 3. Each line represents the expected wage for a given probability $(p)$ of obtaining a high output when the agent exerts high effort.

For our set of parameters, Figure 2 shows that when the level of uncertainty is high $(p=0.4)$, going from no identification $(i=0)$ to full identification $(i=1)$ may result in a reduction of $\$ 1,165$ in agency costs. However, the reduction is only $\$ 110$ when the level of uncertainty is lower $(p=0.7)$. Again, our numerical example illustrates that highly idiosyncratic family business can economize more on agency costs by hiring strongly identified family managers who, by virtue of their previous involvement with the firm, are probably more able to get a high output from the higher effort induced by the incentive contract.

The previous examples illustrate the ability of our enhanced principal-agent model to explain why family managers need less compensation and incentives vis-à-vis nonfamily managers. In the next section, we discuss two contextual factors that can potentially influence the relationship between the optimal contract parameters and organizational identification in family firms. 


\section{Organizational and Situational Factors}

In our model, we introduce the concept of organizational identification to understand how the existence of family ties between principal and agent shape the characteristics of optimal incentive contracts. Besides improving the explanatory power of the principal-agent model in the domain of family firms, we propose that our model also offers a framework that accommodates important contextual factors in that domain.

For instance, Lubatkin, Durand and Ling (2007, p. 1026) suggested that psychosocial altruism, defined as "the endogenous propensity for parents to transfer predefined socially embedded values and norms to their offspring", is associated with governance efficiencies in family firms. In families with high levels of such altruistic behaviors, a flow of actions from parents to children convey basic incentives, such as love and nurturing, as well as complex ones, like ethical clarity and socialization (Lubatkin, Durand et al., 2007). The authors argue that through these actions parents create a family bond that "transfer a history, identity, and language to the family firm" (p. 1027). As a result, we expect that family firms that are impregnated with higher levels of psychosocial altruism flowing from family owners to other members of the family will benefit from having strongly identified family managers, hence reducing agency costs.

The inclusion of organizational identification in our principal-agent model also allows us to accommodate variations in the cultural setting in which the family firm is embedded, and thus overcome a common critique of principal-agent analysis (Lubatkin, Lane et al., 2007). As Sundaramurthy and Kreiner (2008) and others have argued, cultural aspects can influence the ways family businesses create, maintain, and negotiate role identities. Indeed, research has found that individualism and collectivism account for relevant variation in work-related attitudes, human resources management practices and organizational group behavior (Earley, 1993; Hui, Yee, \& Eastman, 1995; Ramamoorthy \& Carroll, 1998).

In the context of this work, individualism and collectivism are relevant cultural traits since they refer to the ways individuals integrate into social groups in a given society (Hofstede, 2001). In individualist societies, people tend to maintain loosely knit social relations in which individuals expect that others will rarely interfere in their affairs (Greif, 1994; Licht, Goldschmidt, \& Schwartz, 2007). People see themselves as autonomous and independent (Chen, Peng, \& Saparito, 2002), and when interests are in conflict, individuals generally give precedence to their own interests (Oyserman, Coon, \& Kemmelmeier, 2002; Triandis, 1995). The United States, Australia, the United Kingdom, the Netherlands, Canada and Italy are countries in which individualist traits prevail, according to Hofstede's (1980) seminal work.

Collectivist cultures are characterized by the preponderance of close-knit relations between individuals, who also feel involved in the lives of other members of their group (Greif, 2008; Licht et al., 2007). Embeddedness and group interdependence overcome the individual need for self-expression (Falicov, 2001). Latin American countries are examples of collectivist societies, along with several Asian countries (Hofstede, 1984).

What is central to our model is that strong in-group identification, which is mainly based on values such as belonging and tradition, is essential to the definition of collectivism (Triandis, McCusker, \& Hui, 1990). Equally important, collectivism is related to both the size of social groups (Falicov, 2001; Greif, 1994; Hofstede, 1980; Licht et al., 2007) and the strength with which individuals feel attached to these groups. In collectivist countries the family, kin and friends form a complex network, which circumvents nuclear households, and group members are partially responsible for each others' welfare. In these settings, we reason that the influence of family in the firms is stronger than in individualist cultures. More specifically, we expect that the effect of psychosocial altruism on the organizational identification of family managers is still higher for firms in collectivist countries than those in individualist countries. 
Moreover, the features of collectivist cultures create conditions that extend the influence of the family towards nonfamily employees in the family firm. First, as Zahra, Hayton, Neubaum, Dibrell and Craig (2008) suggested, affective feelings towards the firm on the part of the family can create a similar response among employees. Research suggests that positive emotions are transmitted among people in a group, with group members experiencing improved cooperation, decreased conflict and increased perceived task performance (Barsade, 2002). Second, sharing values does not necessarily require kinship ties. In fact, the perception of who is part of the family has been observed to be fluid in family firms in collectivist cultures, including nonconsanguineous members who have become part of a specific inner team of employees (Karra, Tracey, \& Phillips, 2006; Pagliarussi \& Rapozo, 2011).

The literature on family firms provides examples of practices used to induce a sense of belongingness to nonfamily employees in collectivist societies. Karra, Tracey and Phillips (2006) reported in their case study of a Turkish family firm that many of their interviewees stressed that they were indebted to the company's founder for offering them employment and also said that they felt very well taken care of. Other acts of generosity by the owner of the firm towards his kin were mentioned, such as "he financed the education of several of the children of his employees and paid for their medical expenses and weddings" (Karra et al., 2006, p. 870). The authors also observed that the owner of the company referred to his distributors as friends, while his distributors often referred to him as a family member, father or uncle.

Pagliarussi and Rapozo (2011) reported in their case study the use of practices such as the owner of the firm helping his employee to start a new business initiative, both with financial and with operational resources; inviting friends and family members to participate in the expansion of the business, allowing them to buy shares in new stores and pay with work, and hiring people based on kinship ties. The authors argue such actions contributed to create an extended family in the firm, thus fostering trust among the in-groups and depressing agency problems.

Therefore, we expect that when a family firm in a collectivist country needs to appoint a new manager, it will have access to a pool of prospective employees that have already experienced a positive level of identification with the firm. This pool includes highly identified family members, as well as moderately identified nonfamily candidates. Hence, we propose that family firms in collectivist countries will be able to further economize on agency costs, vis-à-vis family firms in individualist countries.

\section{Conclusions}

In this paper, we addressed the issue of executive compensation in family firms. We modeled a situation in which a family firm needs to hire a manager and the family owner can offer a contract to a family member or to an outside manager. Results from previous works suggest that family managers would demand lower compensation and less incentive than nonfamily managers would to perform their tasks. The literature on executive compensation in family firms not only offer several distinct explanations for this pattern of results, but also call into question the use of agency theory in the domain of family firms.

Based on the concept of organizational identification, we introduced a term in our principal-agent model that captures the influence of family ties on the agent's behavior. We showed that our enhanced principal-agent model offers a unifying framework that reconciles the findings of previous studies about executive compensation in family firms, specifically regarding agency costs and the risk sharing properties of incentive contracts designed to align interests between principals and agents who share family ties.

Additionally, the introduction of organizational identification in our model makes it flexible to accommodate variations in the characteristics family firms, and in the cultural setting in which those 
firms are embedded. We explored two of these factors, respectively the intensity of psychosocial altruism flowing from family owners to family members, and the level of collectivism of the society. Thus, our model is both family firm specific and it fills a gap in the knowledge about how formal and informal institutions at a country level affect behaviors in family firms (Carney et al., 2015; Pindado \& Requejo, 2014).

\section{Limitations and future research}

A clear limitation of our model is the reliance on individualism and collectivism to express cultural variation. Future research could include other dimensions from Hofstede's (1980) model into our framework. The power distance cultural dimension arguably affects agency relationships in family firms, because power is concentrated in the sole hands of the family and thus power differences between family and nonfamily members are more pronounced. In cultures with high power distance scores, such differences could influence organizational identification.

Another important limitation in our model is that we only considered the influence of noneconomic concerns on the agent's decisions. Future research should work on the integration of our model with the socioemotional wealth (SEW) framework, in order to include noneconomic motivations in the principal's behavior too. Nevertheless, we believe that our model offers an important step in this direction since, consistent with current SEW literature, it attests the rationality of appointing family members for managerial positions in family firms.

The three propositions of the model can be written as the hypothesis and tested in an empirical article. In order to do so, the researcher will require a dataset containing information about compensations, both fixed and variable, and some measure of organizational identification, in particular if the agents have family ties with the principals. Our predictions suggesting that family firms face lower agency costs in collectivist societies need to be tested as well. Also, having information from multiple periods and countries with different cultures (collectivists and individualists), ideally in a panel data format, would certainly increase the potential for additional empirical tests and may further develop the model. Hence, when testing the determinant of executive compensation, researchers should allow it to vary across countries. Although executive compensation can lead to a reduction in agency costs, it must be socially legitimate within its specific social context. Thus, a complex set of institutional factors may influence the structure, size, and effectiveness of executive compensation schemes. Such factors include the dispersion of share ownership, the roles of stakeholders, the tolerance to income inequality, and reputational concerns that frame managerial behavior (Filatotchev, Jackson, \& Nakajima, 2013). Therefore, measures such as in-firm experience may appear as an important factor determining executive compensation in collectivist countries, such as India and other emerging economies, an evidence already found in Ghosh (2006).

In addition, future studies should consider that even though executive compensation can lead to a reduction of agency costs, it must be socially legitimate within its specific social context. Thus, a complex set of institutional factors may influence the structure, size, and effectiveness of executive compensation schemes. Such factors include the dispersion of share ownership, the roles of stakeholders, the tolerance to income inequality, and reputational concerns that frame managerial behavior (Filatotchev et al., 2013).

\section{Implications for practice}

From a practical point of view, our framework suggests that family firms strongly benefit from investments directed to increase the spread of a particular culture, including an ideology, symbols and customized socialization routines, especially those firms in collectivist societies. As Akerlof and Kranton (2005) remarked, a change in identity is the ideal motivator when the effort of a worker is either hard to observe or hard to reward. In this sense, excessive reliance on tight control mechanisms may prove counterproductive, since those mechanisms will be onerous on the firm and actually induce nonfamily managers to behave as out-groups. 


\section{References}

Abernethy, M. A., Bouwens, J., \& Kroos, P. (2017). Organization identity and earnings manipulation. Accounting, Organizations and Society, 58, 1-14. https://doi.org/10.1016/j.aos.2017.04.002

Adler, P. A., \& Adler, P. (1988). Intense loyalty in organizations: A case study of college athletics. Administrative Science Quarterly, 33(3), 401-417. https://doi.org/10.2307/2392716

Akerlof, G. A., \& Kranton, R. E. (2005). Identity and the economics of organizations. The Journal of Economic Perspectives, 19(1), 9-32. https://doi.org/10.1257/0895330053147930

Anderson, R. C., \& Reeb, D. M. (2003). Founding-family ownership and firm performance: Evidence from the S\&P 500. The Journal of Finance, 58(3), 1301-1327. https://doi.org/10.1111/15406261.00567

Ashforth, B. E., \& Mael, F. (1989). Social identity theory and the organization. Academy of Management Review, 14(1), 20-39. https://doi.org/10.2307/258189

Ashforth, B. E., \& Mael, F. A. (1996). Organizational identity and strategy as a context for the individual. In P. Shrivastava, A. S. Huff, \& J. E. Dutton (Eds.), Advances in strategic management (Vol. 13, pp. 19-64). Greenwich, CT: JAI Press.

Astrachan, J. H., \& Jaskiewicz, P. (2008). Emotional returns and emotional costs in privately held family businesses: Advancing traditional business valuation. Family Business Review, 21(2), 139-149. https://doi.org/10.1111/j.1741-6248.2008.00115.x

Baek, H. Y., \& Fazio, P. L. (2015). The effect of family ownership and control on equity-based compensation: Evidence from S\&P SmallCap firms. Journal of Family Business Management, 5(1), 55-72. https://doi.org/10.1108/jfbm-04-2014-0008

Barsade, S. G. (2002). The ripple effect: Emotional contagion and its influence on group behavior. Administrative Science Quarterly, 47(4), 644-675. https://doi.org/10.2307/3094912

Berghe, L. A. A., \& Carchon, S. (2003). Agency relations within the family business system: An exploratory approach. Corporate Governance: An International Review, 11(3), 171-179. https://doi.org/10.1111/1467-8683.00316

Bhattacharya, C. B., Rao, H., \& Glynn, M. A. (1995). Understanding the bond of identification: An investigation of its correlates among art museum members. Journal of Marketing, 59(4), 46-58. https://doi.org/10.2307/1252327

Block, J. H. (2011). How to pay a non-family managers in large family firms: A principal-agent model. Family Business Review, 24(1), 9-27. https://doi.org/10.1177/0894486510394359

Block, J. H., Millán, J. M., Román, C., \& Zhou, H. (2015). Job satisfaction and wages of family employees. Entrepreneurship Theory and Practice, 39(2), 183-207. https://doi.org/10.1111/etap.12035

Boivie, S., Lange, D., McDonald, M. L., \& Westphal, J. D. (2011). Me or we: The effects of CEO organizational identification on agency costs. Academy of Management Journal, 54(3), 551-576. https://doi.org/10.5465/amj.2011.61968081

Carney, M. (2005). Corporate governance and competitive advantage in family-controlled firms. Entrepreneurship Theory and Practice, 29(3), 249-265. https://doi.org/10.1111/j.15406520.2005.00081.x 
Carney, M., Van Essen, M., Gedajlovic, E. R., \& Heugens, P. P. (2015). What do we know about private family firms? A meta-analytical review. Entrepreneurship Theory and Practice, 39(3), 513-544. https://doi.org/10.1111/etap.12054

Chen, C. C., Peng, M. W., \& Saparito, P. A. (2002). Individualism, collectivism, and opportunism: A cultural perspective on transaction cost economics. Journal of Management, 28(4), 567-583. https://doi.org/10.1177/014920630202800405

Chrisman, J. J., Chua, J. H., \& Litz, R. A. (2004). Comparing the agency costs of family and non-family firms: Conceptual issues and exploratory evidence. Entrepreneurship Theory and Practice, 28(4), 335-354. https://doi.org/10.1111/j.1540-6520.2004.00049.x

Chrisman, J. J., Chua, J. H., \& Sharma, P. (2005). Trends and directions in the development of a strategic management theory of the family firm. Entrepreneurship Theory and Practice, 29(5), 555-576. https://doi.org/10.1111/j.1540-6520.2005.00098.x

Chrisman, J. J., Chua, J. H., \& Steier, L. (2005). Sources and consequences of distinctive familiness: An introduction. Entrepreneurship Theory and Practice, 29(3), 237-247. https://doi.org/10.1111/j.1540-6520.2005.00080.x

Chrisman, J. J., Kellermanns, F. W., Chan, K. C., \& Liano, K. (2010). Intellectual foundations of current research in family business: An identification and review of 25 influential articles. Family Business Review, 23(1), 9-26. https://doi.org/10.1177/0894486509357920

Chua, J. H., Chrisman, J. J., \& Sharma, P. (1999). Defining the family business by behavior. Entrepreneurship Theory and Practice, 23(4), 19-40.

Corbetta, G., \& Salvato, C. A. (2004). The board of directors in family firms: One size fits all?. Family Business Review, 17(2), 119-134. https://doi.org/10.1111/j.1741-6248.2004.00008.x

Cruz, C. C., Gómez-Mejia, L. R., \& Becerra, M. (2010). Perceptions of benevolence and the design of agency contracts: CEO-TMT relationships in family firms. Academy of Management Journal, 53(1), 69-89. https://doi.org/10.5465/amj.2010.48036975

Davis, J. H., Allen, M. R., \& Hayes, H. D. (2010). Is blood thicker than water? A study of stewardship perceptions in family business. Entrepreneurship Theory and Practice, 34(6), 1093-1116. https://doi.org/10.1111/j.1540-6520.2010.00415.x

Dukerich, J. M., Golden, B. R., \& Shortell, S. M. (2002). Beauty is in the eye of the beholder: The impact of organizational identification, identity and image on the cooperative behaviors of physicians. Administrative Science Quarterly, 47(3), 507-533. https://doi.org/10.2307/3094849

Dutton, J. E., \& Penner, W. J. (1993). The importance of organizational identity for strategic agenda building. In J. Hendry, \& G. Johnson (Eds.), Strategic thinking: Leadership and the management of change (pp. 89-113). New York: John Wiley \& Sons.

Earley, P. C. (1993). East meets West meets Mideast: Further explorations of collectivistic and individualistic work groups. Academy of Management Journal, 36(2), 319-348. https://doi.org/10.2307/256525

Falicov, C. J. (2001). The cultural meanings of money: The case of Latinos and Anglo-Americans. American Behavioral Scientist, 45(2), 313-328. http://dx.doi.org/10.1177/00027640121957088

Filatotchev, I., Jackson, G., \& Nakajima, C. (2013). Corporate governance and national institutions: A review and emerging research agenda. Asia Pacific Journal of Management, 30(4), 965-986. https://doi.org/10.1007/s10490-012-9293-9 
Ghosh, A. (2006). Determination of executive compensation in an emerging economy: Evidence from India. Emerging Markets Finance and Trade, 42(3), 66-90. https://doi.org/10.2753/ree1540496x420304

Gomez-Mejia, L. R., Larraza-Kintana, M., \& Makri, M. (2003). The determinants of executive compensation in family-controlled public corporations. Academy of Management Journal, 46(2), 226-237. https://doi.org/10.2307/30040616

Gomez-Mejia, L. R., Nuñez-Nickel, M., \& Gutierrez, I. (2001). The role of family ties in agency contracts. Academy of Management Journal, 44(1), 81-95. https://doi.org/10.2307/3069338

Greif, A. (1994). Cultural beliefs and the organization of society: A historical and theoretical reflection on collectivist and individualist societies. Journal of Political Economy, 102(5), 912-950. https://doi.org/10.1086/261959

Greif, A. (2008). Coercion and exchange: How did markets evolve? Retrieved from http://www.stanford.edu/ avner/Greif_Papers/2008\%20Coercion\%20and\%20Exchange.\%20Ho w\%20did\%20Markets\%20Evolve.pdf

Habbershon, T. G. (2006). Commentary: A framework for managing the familiness and agency advantages in family firms. Entrepreneurship Theory and Practice, 30(6), 879-886. https://doi.org/10.1111/j.1540-6520.2006.00158.x

Hart, O., \& Holmström, B. (1986). The theory of contracts [Working Paper no. 418]. Department of Economics, Massachusetts Institute of Technology, Cambridge, MA, USA. Retrieved from https://dspace.mit.edu/bitstream/handle/1721.1/64265/theoryofcontract00hart.pdf\%3Bjs essionid\%3DD2F89D14123801EBB5A616B328AB8CFC?sequence\%3D1

Hart, O., \& Holmström, B. (1987). The theory of contracts. In T. F. Bewley (Ed.), Advances in economic theory: Fifth world congress (pp. 71-155). Cambridge, UK: Cambridge University Press.

Heinle, M. S., Hofmann, C., \& Kunz, A. H. (2012). Identity, incentives, and the value of information. The Accounting Review, 87(4), 1309-1334. https://doi.org/10.2308/accr-50156

Hofstede, G. (1980). Culture and organizations. International Studies of Management \& Organization, 10(4), 15-41. http://dx.doi.org/10.1080/00208825.1980.11656300

Hofstede, G. (1984). Culture's consequences: International differences in work-related values. Newbury Park, CA: Sage.

Hofstede, G. H. (1991). Culture and organizations: Software of the mind. London: McGraw Hill

Hofstede, G. (2001). Culture's consequences: Comparing values, behaviors, institutions, and organizations across nations (2nd ed.). Thousand Oaks, CA: Sage.

Holmstrom, B. (1979). Moral hazard and observability. The Bell Journal of Economics, 10(1), 74-91. https://doi.org/10.2307/3003320

Hui, C. H., Yee, C., \& Eastman, K. L. (1995). The relationship between individualism-Collectivism and job satisfaction. Applied Psychology, 44(3), 276-282. https://doi.org/10.1111/j.14640597.1995.tb01080.x

Jaskiewicz, P., \& Klein, S. (2007). The impact of goal alignment on board composition and board size in family businesses. Journal of Business Research, 60(10), 1080-1089. https://doi.org/10.1016/j.jbusres.2006.12.015 
Karra, N., Tracey, P., \& Phillips, N. (2006). Altruism and agency in the family firm: Exploring the role of family kinship and ethnicity. Entrepreneurship Theory and Practice, 30(6), 861-878. https://doi.org/10.1111/j.1540-6520.2006.00157.x

Lambert, R. A. (2001). Contracting theory and accounting. Journal of Accounting and Economics, 32(1), 3-87. https://doi.org/10.1016/s0165-4101(01)00037-4

Lee, K. S., Lim, G. H., \& Lim, W. S. (2003). Family business succession: Appropriation risk and choice of successor. Academy of Management Review, 28(4), 657-666. https://doi.org/10.5465/amr.2003.10899446

Licht, A. N., Goldschmidt, C., \& Schwartz, S. H. (2007). Culture rules: The foundations of the rule of law and other norms of governance. Journal of Comparative Economics, 35(4), 659-688. https://doi.org/10.1016/j.jce.2007.09.001

Lubatkin, M. H., Durand, R., \& Ling, Y. (2007). The missing lens in family firm governance theory: A self-other typology of parental altruism. Journal of Business Research, 60(10), 1022-1029. https://doi.org/10.1016/j.jbusres.2006.12.019

Lubatkin, M., Lane, P. J., Collin, S., \& Very, P. (2007). An embeddedness framing of governance and opportunism: Towards a cross-nationally accommodating theory of agency. Journal of Organizational Behavior, 28(1), 43-58. https://doi.org/10.1002/job.402

Macho-Stadler, I., \& Pérez-Castrillo, J. D. (2001). An introduction to the economics of information: Incentives and contracts. New York: Oxford University Press.

Madison, K., Holt, D. T., Kellermanns, F. W., \& Ranft, A. L. (2015). Viewing family firm behavior and governance through the lens of agency and stewardship theories. Family Business Review, 28(4), 312-331. https://doi.org/10.1177/0894486515594292

Mael, F. A., \& Ashforth, B. E. (1992). Alumni and their alma mater: A partial tests of the reformulated model of organizational identification. Journal of Organizational Behavior, 13(2), 103-123. https://doi.org/10.1002/job.4030130202

McConaughy, D. L. (2000). Family CEOs vs. nonfamily CEOs in the family-controlled firm: An examination of the level and sensitivity of pay to performance. Family Business Review, 13(2), 121-131. https://doi.org/10.1111/j.1741-6248.2000.00121.x

Milgrom, P., \& Roberts, J. (1992). Economics, organization and management. New York: PrenticeHall.

Mustakallio, M., Autio, E., \& Zahra, S. A. (2002). Relational and contractual governance in family firms: Effects on strategic decision making. Family Business Review, 15(3), 205-222. https://doi.org/10.1111/j.1741-6248.2002.00205.x

Oyserman, D., Coon, H. M., \& Kemmelmeier, M. (2002). Rethinking individualism and collectivism: Evaluation of theoretical assumptions and meta-analyses. Psychological Bulletin, 128(1), 3-72. https://doi.org/10.1037//0033-2909.128.1.3

Pagliarussi, M. S., \& Rapozo, F. O. (2011). Agency relationships in a Brazilian multifamily firm. Family Business Review, 24(2), 170-183. https://doi.org/10.1177/0894486511409573

Pindado, J., \& Requejo, I. (2014). Family business performance from a governance perspective: A review of empirical research. International Journal of Management Reviews, 17(3), 279-311. https://doi.org/10.1111/ijmr.12040 
Prencipe, A., Bar-Yosef, S., \& Dekker, H. C. (2014). Accounting research in family firms: Theoretical and empirical challenges. European Accounting Review, 23(3), 361-385. https://doi.org/10.1080/09638180.2014.895621

Prendergast, C. (1999). The provision of incentives in firms. Journal of Economic Literature, 37(1), 763. https://doi.org/10.1257/jel.37.1.7

Ramamoorthy, N., \& Carroll, S. J. (1998). Individualism/collectivism orientations and reactions toward alternative human resource management practices. Human Relations, 51(5), 571-588. https://doi.org/10.1177/001872679805100501

Salvato, C., \& Moores, K. (2010). Research on accounting in family firms: Past accomplishments and future challenges. Family Business Review, 23(3), 193-215. https://doi.org/10.1177/0894486510375069

Schulze, W. S., \& Gedajlovic, E. R. (2010). Whither family business? Journal of Management Studies, 47(2), 191-204. http://dx.doi.org/10.1111/j.1467-6486.2009.00887.x

Schulze, W. S., Lubatkin, M. H., Dino, R. N., \& Buchholtz, A. K. (2001). Agency relationships in family firms: Theory and evidence. Organization Science, 12(1), 99-116. https://doi.org/10.1287/orsc.12.2.99.10114

Sharma, P., \& Irving, P. G. (2005). Four bases of family business successor commitment: Antecedents and consequences. Entrepreneurship Theory and Practice, 29(1), 13-33. https://doi.org/10.1111/j.1540-6520.2005.00067.x

Songini, L., Gnan, L., \& Malmi, T. (2013). The role and impact of accounting in family business. Journal of Family Business Strategy, 4(2), 71-83. https://doi.org/10.1016/j.jfbs.2013.04.002

Speckbacher, G., \& Wentges, P. (2012). The impact of family control on the use of performance measures in strategic target setting and incentive compensation: A research note. Management Accounting Research, 23(1), 34-46. https://doi.org/10.1016/j.mar.2011.06.002

Sundaramurthy, C., \& Kreiner, G. E. (2008). Governing by managing identity boundaries: The case of family businesses. Entrepreneurship Theory and Practice, 32(3), 415-436. https://doi.org/10.1111/j.1540-6520.2008.00234.x

Tagiuri, R., \& Davis, J. A. (1996). Bivalent attributes of the family firm. Family Business Review, 9(2), 199-208. https://doi.org/10.1111/j.1741-6248.1996.00199.x

Triandis, H. C. (1995). Individualism and collectivism. Boulder, CO: Westview Press.

Triandis, H. C., McCusker, C., \& Hui, C. H. (1990). Multimethod probes of individualism and collectivism. Journal of Personality and Social Psychology, 59(5), 1006-1020. https://doi.org/10.1037//0022-3514.59.5.1006

Turner, J. C. (1982). Towards a cognitive redefinition of the social group. In H. Tajfel (Ed.), Social identity and intergroup relations (pp. 15-40). Cambridge, England: Cambridge University Press.

Verbeke, A., \& Kano, L. (2010). Transaction cost economics (TCE) and the family firm. Entrepreneurship Theory and Practice, 34(6), 1173-1182. https://doi.org/10.1111/j.15406520.2010.00419.x

Villalonga, B., \& Amit, R. (2006). How do family ownership, control and management affect firm $\begin{array}{llll}\text { value?. Journal of Financial Economics, } & 80(2), & 385-417 .\end{array}$ https://doi.org/10.1016/j.jfineco.2004.12.005 
Whetten, D. A. (1989). What constitutes a theoretical contribution?. Academy of Management Review, 14(4), 490-495. https://doi.org/10.2307/258554

Zahra, S. A., Hayton, J. C., Neubaum, D. O., Dibrell, C., \& Craig, J. (2008). Culture of family commitment and strategic flexibility: The moderating effect of stewardship. Entrepreneurship Theory and Practice, 32(6), 1035-1054. https://doi.org/10.1111/j.1540-6520.2008.00271.x

Zellweger, T. M., \& Astrachan, J. H. (2008). On the emotional value of owning a firm. Family Business Review, 21(4), 347-363. https://doi.org/10.1111/j.1741-6248.2008.00129.x

Zellweger, T. M., Eddleston, K. A., \& Kellermanns, F. W. (2010). Exploring the concept of familiness: Introducing family firm identity. Journal of Family Business Strategy, 1(1), 54-63. https://doi.org/10.1016/j.jfbs.2009.12.003

\section{Authors' Profiles}

\section{Marcelo Sanches Pagliarussi}

USP, Av. Bandeirantes, 3900, Monte Alegre, 14040-905, Ribeirão Preto, SP, Brazil. E-mail address: marcelosp@ usp.br

Cristiano Costa

Unisinos - Porto Alegre, Av. Luiz Manoel Gonzaga, 744, 90470-280, Porto Alegre, RS, Brazil. E-mail address: cristianocosta@unisinos.br 


\section{APPENDIX}

\section{Proof of Proposition 1}

The problem of the principal is finding a contract $\left(w^{L}, w^{H}\right)$ such that:

$$
\max _{\left(w^{L}, w^{H}\right)} E[y(e)-w(y(e))]
$$

s.t.

$$
\begin{aligned}
& E\left[U\left(e^{H}\right)\right] \geq \bar{U} \\
& E\left[U\left(e^{H}\right)\right] \geq E\left[U\left(e^{L}\right)\right]
\end{aligned}
$$

The optimal contract has to be such that:

$$
\begin{aligned}
& p \sqrt{w^{H}}+(1-p) \sqrt{w^{L}}-e^{H}+i \sqrt{e^{H}} \geq \bar{U} \\
& p \sqrt{w^{H}}+(1-p) \sqrt{w^{L}}-e^{H}+i \sqrt{e^{H}} \geq q \sqrt{w^{H}}+(1-q) \sqrt{w^{L}}
\end{aligned}
$$

Because the principal is risk-neutral, these conditions will hold with equality. Therefore:

$$
\sqrt{w^{H}}=\left(\frac{\bar{U}-(1-p) \sqrt{w^{L}}+e^{H}-i \sqrt{e^{H}}}{p}\right)
$$

Substitute this into equation (2) to obtain:

$$
\begin{gathered}
p\left(\frac{\bar{U}-(1-p) \sqrt{w^{L}}+e^{H}-i \sqrt{e^{H}}}{p}\right)+(1-p) \sqrt{w^{L}}-e^{H}+i \sqrt{e^{H}} \\
=q\left(\frac{\bar{U}-(1-p) \sqrt{w^{L}}+e^{H}-i \sqrt{e^{H}}}{p}\right)+(1-q) \sqrt{w^{L}} \\
\bar{U}-(1-p) \sqrt{w^{L}}+e^{H}-i \sqrt{e^{H}}+(1-p) \sqrt{w^{L}}-e^{H}+i \sqrt{e^{H}} \\
=\frac{q}{p} \bar{U}-\frac{q(1-p)}{p} \sqrt{w^{L}}+\frac{q}{p} e^{H}-\frac{q}{p} i \sqrt{e^{H}}+(1-q) \sqrt{w^{L}} \\
\frac{(p-q)}{p} \bar{U}=\frac{(p-q)}{p} \sqrt{w^{L}}+\frac{q}{p} e^{H}-\frac{q}{p} i \sqrt{e^{H}} \\
\sqrt{w^{L}}=\bar{U}+\frac{q}{(p-q)} i \sqrt{e^{H}}-\frac{q}{(p-q)} e^{H}
\end{gathered}
$$

Substitute (2) back into (1) to obtain:

$$
\begin{aligned}
\sqrt{w^{H}} & =\left(\frac{\bar{U}-(1-p)\left[\bar{U}+\frac{q}{(p-q)} i \sqrt{e^{H}}-\frac{q}{(p-q)} e^{H}\right]+e^{H}-i \sqrt{e^{H}}}{p}\right) \\
\sqrt{w^{H}} & =\bar{U}-\frac{(1-q)}{(p-q)} i \sqrt{e^{H}}+\frac{(1-q)}{(p-q)} e^{H}
\end{aligned}
$$


Therefore, the optimal contract $\left(w^{L *}, w^{H *}\right)$ is:

$$
\begin{gathered}
w^{L *}=\left[\bar{U}+\frac{q}{p-q} i \sqrt{e^{H}}-\frac{q}{p-q} e^{H}\right]^{2} \\
w^{H *}=\left[\bar{U}-\frac{(1-q)}{p-q} i \sqrt{e^{H}}+\frac{(1-q)}{p-q} e^{H}\right]^{2}
\end{gathered}
$$

A sufficient condition to ensure that $w^{H *}>w^{L *}$ for all levels of organizational identification is $e^{H}>1$.

\section{Proof of Proposition 2} we obtain:

We need to show that $w^{L *}$ is increasing in $i$ while $w^{H *}$ is decreasing in $i$. By taking derivatives,

$$
\begin{gathered}
\frac{\delta w^{L *}}{\delta i}=2\left[\bar{U}+\frac{q}{p-q} i \sqrt{e^{H}}-\frac{q}{p-q} e^{H}\right]\left(\frac{q}{p-q}\right) \sqrt{e^{H}}>0 \\
\frac{\delta w^{H *}}{\delta i}=-2\left[\bar{U}-\frac{(1-q)}{p-q} i \sqrt{e^{H}}+\frac{(1-q)}{p-q} e^{H}\right]\left(\frac{1-q}{p-q}\right) \sqrt{e^{H}}<0
\end{gathered}
$$

Because we are assuming that $e^{H}>1$, the expression in brackets is positive and the condition is satisfied.

\section{Proof of Proposition 3}

The expected cost of inducing high effort is:

$$
E[w]=p w^{H *}+(1-p) w^{L *}
$$

When there is a positive level of organizational identification, this cost is:

$$
E[w]_{i>0}=p\left[\bar{U}-\frac{(1-q)}{p-q} i \sqrt{e^{H}}+\frac{(1-q)}{p-q} e^{H}\right]^{2}+(1-p)\left[\bar{U}+\frac{q}{p-q} i \sqrt{e^{H}}-\frac{q}{p-q} e^{H}\right]^{2}
$$

When the level of organizational identification is zero, the expected cost is:

$$
E[w]_{i=0}=p\left[\bar{U}+\frac{(1-q)}{p-q} e^{H}\right]^{2}+(1-p)\left[\bar{U}-\frac{q}{p-q} e^{H}\right]^{2}
$$

The difference between $E[w]_{i>0}$ and $E[w]_{i=0}$ is given by:

$$
\begin{gathered}
\Delta=-\bar{U} \frac{p(1-q)}{p-q} i \sqrt{e^{H}}+p\left(\frac{(1-q)}{p-q} i \sqrt{e^{H}}\right)^{2}-p \frac{(1-q)^{2}}{(p-q)^{2}} i e^{3 / 2 H}+\bar{U} \frac{(1-p) q}{p-q} i \sqrt{e^{H}}+(1-p)\left(\frac{q}{p-q} i \sqrt{e^{H}}\right)^{2}-(1 \\
-p) \frac{q^{2}}{(p-q)^{2}} i e^{3 / 2 H} \\
\Delta=\frac{(1-p) q-p(1-q)}{p-q} \bar{U} i \sqrt{e^{H}}+\frac{p(1-q)^{2}}{(p-q)^{2}}\left[i^{2} e^{H}-i(f, c) e^{3 / 2 H}\right]+\frac{(1-p) q^{2}}{(p-q)^{2}}\left[i^{2} e^{H}-i e^{3 / 2 H}\right]
\end{gathered}
$$




$$
\Delta=-\bar{U} i \sqrt{e^{H}}+\frac{p(1-q)^{2}+(1-p) q^{2}}{(p-q)^{2}}\left[i^{2} e^{H}-i e^{3 / 2 H}\right]
$$

Remember that we are assuming that $p>q$ and that $e^{H}>1$. Hence, $\Delta<0$, which implies that $E[w]_{i>0}<E[w]_{i=0}$. 